SIR-The first published account of success in immobilizing antiprotons in an electromagnetic trap has been the subject of a recent leading article in News and Views (Nature 324, 299; 1986). Although this article gives a good overview of the scientific meaning of this historical achievement, it gives in our view a rather misleading perspective on its likely military significance.

It is true that for some applications of antimatter, such as antiballistic missile or spacecraft propulsion, relatively large amounts of antiprotons are required. For most other cases, the useful amounts are usually much smaller. For example, we have calculated that less than a microgram of antiprotons is sufficient to trigger a thermonuclear explosion or pump a powerful X-ray laser ${ }^{1,2}$

But antimatter is not only the most portable of all high explosives, it is also the only feasible portable source of muons. In every antiproton annihilation, on average three muons are produced. These could be used to induce muon-catalysed fusion reactions in a deuterium - tritium mixture, an attractive solution for a low-weight space nuclear reactor that could be operated in a continuous or pulsed mode.

Furthermore, by collecting and cooling the muons (an easy task compared with that of cooling antiprotons) a very intense beam could be formed and sent into the atmosphere to guide, over a range of more than $10 \mathrm{~km}$, a series of powerful electron or proton beam pulses towards a target. More simply, stopping the muons in a suitable material would generate an extraordinarily effective X-ray lasing medium, for the two-microsecond lifetime of the muonic atoms.

In outer space, a very low intensity burst of antiprotons would be most suitable for active warhead/decoy discrimination. In this and the two previous examples, the amount of antiprotons needed is of the order of nanograms per engagement. Conservative estimates of the technical problems involved in producing and manipulating microgram amounts of antimatter per day show that known technology is only a couple of orders of magnitudes away from meeting the challenge $e^{2-4}$.

We are very much concerned by the implications for nuclear weapons proliferation of the indisputable scientific feasibility of several antimatter weapon concepts.

1. Gsponer, A \& Humi, J.P. La Recherche 17, 1440-1443 (1986); The Physics of Antimatter Induced Fusion and Ther (1986); The Physics of Antimatter Induced Fus monuclear Explosions, in Proc. 4th Intl. Conf. Emerging Nucl. Energy Syst., Madrid, 30 June-4 July 1986 (in the press).

2. Gsponer. A. \& Hurni, J.-P. Antimatter Induced Fusion and Thermonuclear Explosions, report ISRI-85-05 (August 1985): preprint ISR-86-06 Atomkernenergie/Kerntechnik.

3. Augenstein, B.W. Concepts, Problems and Opportunities for use of Annihilation Energy RAND Note N-2302-AF/RC for use of Annit

4. Walgate, R. Nature 322, 678 (1986).
To develop such weapons would add considerable impetus to the current arms race. We call for an immediate ban on all antimatter-related research, especially as this work is fundamental to many thirdgeneration nuclear weapon systems.

ANDRÉ GSPONER

Jean-Pierre Hurni

Independent Scientific Research Institute,

15, Charles-Galland,

Ch-1206 Geneva,

Switzerland

\section{SDI boycott}

SiR-Your leading article (Nature 323, 746 ; 1986) questioning the wisdom of a boycott of the Strategic Defense Initiative (SDI) misses the point. Scientists who oppose SDI funding do not accept the premise that knowledge is worth gaining for its own sake, irrespective of the ultimate social consequences. We can wait to obtain some knowledge and its gains.

Of course academic researchers should decide for themselves what research they should undertake, but they should also strive to ensure that the knowledge they gain is not applied to ends that are not in the interests of humanity, questions of nationalism aside. Refusing SDI funding is one way of expressing opposition to the political control of science.

We in New Zealand admire the refusnik mentality and although there is no prospect of our being offered SDI money, scientists have played an important role in bolstering the government's policy of refusing port visits by nuclear weaponcapable vessels, of the Royal Navy and the United States Navy in particular.

Department of Physics,

University of Auckland,

Private Bag,

Auckland,

New Zealand

\section{In the greenhouse}

SIR-T.R. Vidyasagar (Nature 323, 390; 1986) suggests a switch to a vegetarian diet and reforestation of the 40 per cent of present agricultural land so freed as a way to decrease atmospheric $\mathrm{CO}_{2}$. This shortterm measure could be supplemented by fertilizing the world's forest and pasture soils, where applicable, with nutrients from city drains, combined with pelleted spores and seeds of soil-enriching plants. Only a light dressing of suitably prepared and selected material would be required to fortify their nutrient cycles and make them more productive for many years. Many parts of the oceans would respond to similar treatment by producing more fish, seaweed, corals and carbonaceous sediments, the latter being the more permanent sink for $\mathrm{CO}_{2}$

Perhaps floating lagoons made to transport sewerage could be towed like icebergs (used for soft water irrigation), to chosen sites, where the surface waters would be fed by trickle and slow release methods. Natural upwelling of nutrientrich bottom waters of the ocean greatly increase their production of living organisms, (J.H. Ryther Science 166, 72-76; 1969) and artificial methods could be developed to extend this process.

I look forward to a time when it is possible by careful balancing of the nutrition of $p \mathrm{H}$ of the biosphere in these and other ways to treble its content of unoxidized C, as has been accomplished on farms and gardens around the world in the course of a few decades.

Arrington Bridge,

R. PARR

Arrington, Royston,

Hertfordshire SG8 OAE, UK

\section{First among equals}

SIR-in a recent leading article (Nature 324, 509; 1986), you ask "Should editors now seek to protect authors from themselves by banning the use of the word 'first'?". My reply is: would you care to join the Proceedings, which has had such a policy for some years?

I do not know exactly when the Proceedings first published priority statements. There is a 1977 memorandum in the files from Bernard K. Forscher, then managing editor, to Robert L. Sinsheimer, then chairman of the editorial board, suggesting such a policy (which may simply be the earliest available written expression of a previously unwritten policy) and a letter from Sinsheimer concurring. Since 1983 at least, the Information for Contributors has stated "The Proceedings does not print priority statements". Thus, one of the duties of our editorial staff is to remove such statements. Most authors accept this change with equanimity; for those who do not, we permit the qualified statement "So far as we know, this is the first...".

A policy that is much more difficult to implement is our proscription of statements of novelty. I admit that this has been unevenly enforced, although in the past year we have become more strict. Novel fragments, novel genes, novel hypothesis - the term is usually a cliché occasioned by the author's desire for an adjective, as our stated policy is to publish reports of exceptional importance and novelty. Again, would you care to join us?

Frances R. Zwanzig (Managing Editor)

Proceedings Office,

National Academy of Sciences,

2101 Constitution Avenue,

Washington, DC 20418, USA 